\title{
Isolation and Identification of Parasitic Protozoa in Sampled Water From the Southwest of Iran
}

\author{
Abdollah Rafiei ${ }^{1}$; Mahmoud Rahdar ${ }^{2, *} ;$ Rohollah Valipour Nourozi $^{3}$ \\ ${ }_{1}^{1}$ Parasitology Department, Medical School and Infectious and Tropical Diseases Researches Center, Ahvaz Jundishapur University of Medical Sciences, Ahvaz, IR Iran \\ ${ }_{2}^{2}$ Parasitology Department, Medical School and Cellular and Molecular Researches Center, Ahvaz Jundishapur University of Medical Sciences, Ahvaz, IR Iran \\ 3 Parasitology Department, Medical School, Ahvaz Jundishapur University of Medical Sciences, Ahvaz, IR Iran \\ ${ }^{*}$ Corresponding author: Mahmoud Rahdar, Parasitology Department, Medical School and Cellular and Molecular Researches Center, Ahvaz Jundishapur University of Medical Sci- \\ ences, Ahvaz, IR Iran. Tel: +98-6113388401/+98-9166153521, Fax:+98-6113332036, E-mail: Mrahdar2002@yahoo.com
}

Received: May 19, 2014; Revised: June 14, 2014; Accepted: June 24, 2014

\begin{abstract}
Background: In spite of promotion of people's hygiene in the recent years, parasitic infection problems are present in many parts of the world especially in tropical and subtropical areas. Water is one of the major sources for acquiring parasitic infections, especially protozoan parasites.

Objectives: This study was conducted to evaluate the present parasitic agents in river, tap water and filtrated water in the western part of Ahvaz city.

Materials and Methods: Forty-four water samples were collected from different sources of the studied area. The samples were examined by routine parasitology methods using light microscopy.

Results: Twenty-eight out of 44 water samples were positive for parasitic contamination with cysts and oocysts of four parasitic protozoa including: 50\% Entamoeba spp (22 out of 44 samples), 27.27\% Cryptosporidium spp (12 out of 44 samples), 13.63\% Blastocystis spp (6 out of 44 samples) and $9.09 \%$ Giardia spp ( 4 out of 44 samples).

Conclusions: The parasite infection rate in water is high and deficits of water quality should be solved by water organization responders. It is strongly recommended to use home filtration systems for consumption of safe water.
\end{abstract}

Keywords:Intestinal Parasite; Cysts; Oocysts; Water

\section{Background}

In despite of the promotion of public health and improvement of life style in the recent years, parasitic diseases have remained a public health problem in many parts of the world. Water is a major source for acquiring several pathogenic agents including bacteria, viruses and parasites. These biological agents can be transmitted via non-sanitized water $(1,2)$. According to World Health Organization reports more than 80 infectious diseases can be transmitted by water (3). Population growth, urbanization, existence of infected animals, climate variations, deficit and elderly of water network system, and hygienic poverty are main factors for the spread of pathogenic parasite agents (1). The World Health Organization has estimated that $40 \%$ of the world's population lives in areas with lack of sanitation (2.4 billion people); 1.1 billion person do not have access to safe water and up to 2.2 million children die annually due to diarrhea (1). Moreover, in developing countries, $60 \%$ of the population do not have access to healthy drinking water (3, 4). During 1920 to 2002 in the United States, at least 1870 water born disease outbreaks were reported with an average of 22.5 reports per year (5). In addition during 1991 to 2002, approximately 207 outbreaks were reported due Giardia and Cryptospo- ridium infection via water in the United States (5). The study on quality and sanitation of water is not only very crucial for public health but also for immunodeficiency individuals in the community (6). There are a few studies on water contamination in Iran, amongst which a study by Ziae reported on water parasite contamination in the Mazandaran province with gastrointestinal protozoan parasites (22). Naeini et al. showed that rivers of Chaharmahal-Bakhtiary province of Iran are contaminated with a variety of parasites (23).

\section{Objectives}

Unfortunately, water quality problems and massive fecal contamination remain unsolved. Therefore studies of water quality and sanitation should be continually performed in most countries especially in tropical areas with defected water network structures. From July to August 2013, an outbreak of gastrointestinal parasitic disease was reported by a health organization located in the west of Ahvaz city, which indicated an increase in prevalence of gastrointestinal diseases in related areas. Therefore this study was conducted to evaluate the mentioned problems.

Copyright (C) 2014, Ahvaz Jundishapur University of Medical Sciences. This is an open-access article distributed under the terms of the Creative Commons Attribution-NonCommercial 4.0 International License (http://creativecommons.org/licenses/by-nc/4.0/) which permits copy and redistribute the material just in noncommercial usages, provided the original work is properly cited. 


\section{Materials and Methods}

\subsection{Sampling}

Forty-four water samples (four litters for each sample) were collected from Golestan, western part Ahvaz city, southwest of Iran. The samples were from three different sources including water refiners (home filter), tap water, before and after treated water and water selling stations during July to August 2013. The water samples were transported to the parasitology department of the medical faculty and were left to stay undisturbed for 24 hours at room temperature (7). The supernatant was sucked and removed (6-8). Sediments of each sample were examined microscopically, as a $0.9 \%$ saline smear, for parasite cysts, trophozoites and helminth eggs $(3,9)$. Samples were stained with Lugol's iodine, modified Ziehl-Neelsen acidfast stain (hot method) and the trichrome technique (9). Descriptive statistical method was used for data analysis.

\section{Results}

Twenty-eight out of 44 water samples were positive for parasitic contamination with cyst and oocysts of four parasitic protozoans including: 50\% Entamoeba spp (22 out of 44 samples), $27.27 \%$ Cryptosporidium spp (12 out of 44 samples), 13.63\% Blastocystis spp (6 out of 44 samples) and $9.09 \%$ Giardia spp (4 out of 44 samples). Table 1 and Figure 1 show the collected parasites from each water sample. There were differences amongst positive samples according to clearance, from low to high turbidity. Table 2 presents the rate of parasitic contamination in the studied samples.

There was not helminthes contamination in the studied water samples. In 28 positive samples the most frequent parasitic contamination was related to Entamoeba spp Cysts, and the least frequent parasitic contamination was related to Giardia spp Cysts. The observed parasitic contaminations included the following infection agents; Entamoeba spp (eight samples), Cryptosporidium spp (three samples) and Blastocystis spp (one sample). There was no parasitic contamination in all three samples from the three waterselling stations. In 20 out of 31 tap water samples, cysts and oocysts of protozoan parasites were detected.
Table 1. Parasites in Ten Samples of Water Refiners of Golestan District

\begin{tabular}{lcc}
\hline No. & Kind of Sample & Result \\
\hline $\mathbf{1}$ & raw water & Entamoeba spp \\
$\mathbf{2}$ & raw water & $\begin{array}{c}\text { Entamoeba spp } \\
\text { Cryptosporidium spp }\end{array}$ \\
$\mathbf{3}$ & raw water & Entamoeba spp \\
$\mathbf{4}$ & treated water & Entamoeba spp \\
$\mathbf{5}$ & treated water & - \\
$\mathbf{6}$ & raw water & Entamoeba spp \\
& & Cryptosporidium spp \\
$\mathbf{7}$ & raw water & Entamoeba spp \\
$\mathbf{8}$ & treated water & - \\
$\mathbf{9}$ & raw water & Entamoeba spp \\
$\mathbf{1 0}$ & raw water & Entamoeba spp \\
& & Blastocystis spp \\
& & Cryptosporidium spp \\
\hline
\end{tabular}
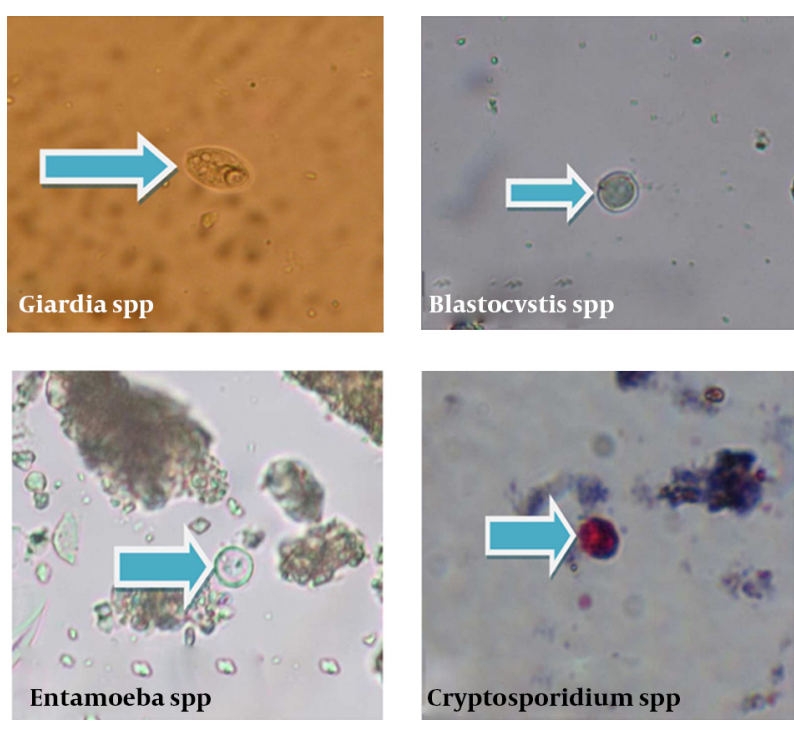

Figure 1. Parasitic Protozoa Detected in Water Samples of Ahvaz City Using Trichrome and Zeil-Nelson Staining During July to August 2013 (Original)

Table 2. Parasitic Infection Frequency of Water Samples Collected From Rivers, Treated Water, Tap Water and Water Selling Stations During July to August 2013

\begin{tabular}{lcccccc}
\hline Parasite & \multicolumn{2}{c}{ Water refiner } & \multicolumn{2}{c}{ Tap water } & \multicolumn{2}{c}{$\begin{array}{c}\text { Water Selling } \\
\text { station (3) }\end{array}$} \\
\cline { 2 - 6 } & $\begin{array}{c}\text { Raw water } \\
\text { (River) (7) }\end{array}$ & $\begin{array}{c}\text { Treated } \\
\text { water (3) }\end{array}$ & $\begin{array}{c}\text { Shahrak Daneshgah } \\
\text { district (10) }\end{array}$ & $\begin{array}{c}\text { Pardis district } \\
\text { (11) }\end{array}$ & $\begin{array}{c}\text { Mojahed } \\
\text { district (5) }\end{array}$ \\
\hline Entamoebaspp & 7 & 1 & 6 & 7 & 1 & 0 \\
Cryptosporidium spp & 3 & 0 & 4 & 4 & 1 & 0 \\
Blastocystisspp & 1 & 0 & 1 & 3 & 1 & 0 \\
Giardia spp & 0 & 0 & 3 & 3 & 2 & 0 \\
$\begin{array}{l}\text { Number of samples without } \\
\text { parasitic contamination }\end{array}$ & 0 & 2 & 6 & & & 3 \\
\hline
\end{tabular}


Rafiei A et al.

\section{Discussion}

There are many researches on evaluation of parasitic contamination of water sources in the world. Recently, Robertson in Norway $(11,12)$, Ono in Japan (13), Briancesco in Italy (14), Azman in Malaysia (15), Gracenea in Spain (10), Khouja in Tunisia (7), Ayaz in Pakistan (3), Bakir in Ankara (9), Hajdu in Sweden (17), Basualdo in Argentina (18), Farias in Brazil (19), Plutzer in Hungary (20), and Nichols in United Kingdom (21) have conducted studies for detection of parasitic contamination of water. In Iran, several studies have been performed in different provinces and cities, Mazandaran (Ziae) (22), Chahrmahal va bakhtyari (Naeini) (23), Ouroomieh (Nanbakhsh) (24) and Kashan (Rasti) (25). The current study indicates that Entamoeba spp cysts were predominant in all district water samples of Ahvaz which is consistent with the study of Ziae (22) from mazandaran and Ayaz (3) from Pakistan. These findings were positively correlated with clinical laboratory reports from Ahvaz, according to which Entamoeba histolytica were more predominant than other protozoan pathogens in gastrointestinal tract of patients. The second most frequent infection was that caused by Cryptosporidium spp that was detected in most positive samples. The results were in agreement with Ayaz and Robertson studies from Pakestan and Norway $(3,12)$ yet were not in agreement with the results of Ziae's study from Mazandaran (22). Moreover we found Blastocystis spp in six samples from 44 (13.63\%). There was no information about Blastocystis contamination in water samples from Iran. Low percentage of water samples were contaminated by Giardia cysts, which does not agree with other investigations from Iran and other parts of the world (22). In this study all samples from Karoon river were contaminated by protozoan parasites. Although no Giardia cysts were isolated from river samples yet in some tap water samples, Giardia cysts were detected. Briancesco from Italy, found a few Giardia cysts in raw water samples (14). This discordance may be due to low number of collected samples in this study. According to this research water entering into water refiners had a low sanitary quality. Three samples of treated water were infected by parasites, which indicated that treatment methods used for refining water was not adequate. Trophozoites are susceptible to most disinfectants but cysts and oocysts remain resistance to chlorination and ozone treatment. Thus the physical removal of Giardia, Entamoeba cysts and Cryptosporidium oocysts by multiple barriers is very important (8). In Ahvaz, most drinking water sources are obtained from surface water, which could be more easily contaminated with parasitic protozoa from animals and human. On the other hand, nearness of the water distributary system to the sewage system, water piped network older than 30 years of age, and using water pumps to raise pressure of water in many houses induced vacuum and drew sewage water from broken water pipe system. In addition, Karoon River is contaminated with industrial sewage materials and wastewater from hospitals. Contamination of drinking water with parasitic agents has not been shown by Briancesco from Italy (14), Bakir from Ankara (9) and researchers of other developed countries yet Ayaz reported drinking water infection in Pakistan (3). Parasitic agents were not seen in market supplied water because of appropriate filter techniques. Helminthes infection was not seen in all studied water samples and this finding agrees with Ziae's study from Mazandaran (22), Khouja from Tunisia (7), Ayaz from Pakistan (3), and Bakir from Ankara (9). The report of helminthes infection by a local medical laboratory showed a significant decrease of this infection in Ahvaz during the recent years. The current findings are correlated with recent waterborne parasite outbreak reports, which show that the majority parasites were protozoans $(97.7 \%)(6,26)$. This study indicated that hygienic quality of water in the studied area is not satisfactory. A number of studies have demonstrated that both Giardia and Cryptosporidium are not only dispersed in tap water but also in bottled water (4). The Entamoeba cyst, a waterborne pathogenic parasite, has been identified to be responsible for serious outbreaks in this area. Giardia spp, Cryptosporidium spp, Entamoeba spp and Blastocystis $s p p$ in water samples, are a potential risk for infection in humans.

The current study showed that the rate of parasitic infections in drinking water is considerably high. The refractory system of water organization should be promoted by using effective disinfect techniques while the reconstruction of pipe water network should be considered. Until the achievement of these goals, personal protection should be done by using house filter systems. Furthermore, to find a seasonal pattern for water contamination, using molecular techniques for precise identification of parasites is recommended.

\section{Acknowledgements}

We specially thank the Ahvaz West Health Office personals for helping collect water samples from rivers, homes and water retailers.

\section{References}

1. Dura G, Kambourova V, Simeonova F, NATO Programme for Security through Science. Management of Intentional and Accidental Water Pollution.: Springer; 2006.

2. Lv S, Tian LG, Liu Q, Qian MB, Fu Q, Steinmann P, et al. Water-related parasitic diseases in China. Int J Environ Res Public Health. 2013;10(5):1977-2016.

3. Ayaz S, Khan S, Khan SN, Bibi F, Shamas S, Akhtar M. Prevalence of Zoonotic Parasites in Drinking Water of Three Districts of Khyber Pakhtunkhwa Province, Pakistan. Pakistan J Life Soc Sci. 2011;9(1):67-9.

4. Karanis P. A review of an emerging waterborne medical important parasitic protozoan. Jpn J Protozool . 2006;39(1).

5. Craun MF, Craun GF, Calderon RL, Beach MJ. Waterborne outbreaks reported in the United States.J Water Health. 2006;4(Suppl 2):19-30.

6. Zarlenga DS, Trout JM. Concentrating, purifying and detecting waterborne parasites. Vet Parasitol. 2004;126(1-2):195-217.

7. Khouja LB, Cama V, Xiao L. Parasitic contamination in wastewa- 
ter and sludge samples in Tunisia using three different detection techniques. Parasitol Res. 2010;107(1):109-16.

8. Bouzid M, Steverding D, Tyler KM. Detection and surveillance of waterborne protozoan parasites. Curr Opin Biotechnol. 2008;19(3):302-6.

9. Bakir B, Tanyuksel M, Saylam F, Tanriverdi S, Araz RE, Hacim AK, et al. Investigation of waterborne parasites in drinking water sources of Ankara, Turkey.J Microbiol Seoul. 2003;41(2):148-51.

10. Gracenea M, Gomez MS, Ramírez CM. Occurrence of Cryptosporidium oocysts and Giardia cysts in water from irrigation channels in Catalonia (NE Spain). Rev Ibero-Latinoam Parasitol. 2011;70(2):172-7.

11. Robertson LJ, Hermansen L, Gjerde BK. Occurrence of Cryptosporidium oocysts and Giardia cysts in sewage in Norway. Appl Environ Microbiol. 2006;72(8):5297-303.

12. Robertson LJ, Gjerde B. Occurrence of Cryptosporidium oocysts and Giardia cysts in raw waters in Norway. Scandinavian J Public Health. 2001;29(3):200-7.

13. Ono K, Tsuji H, Rai SK, Yamamoto A, Masuda K, Endo T, et al. Contamination of river water by Cryptosporidium parvum oocysts in western Japan. Appl Environ Microbiol. 2001;67(9):3832-6.

14. Briancesco R, Bonadonna L. An Italian study on Cryptosporidium and Giardia in wastewater, fresh water and treated water. Environmental Monit Assess. 2005;104(1-3):445-57.

15. Azman J, Init I, Wan Yusoff WS. Occurrence of Giardia and Cryptosporidium (oo)cysts in the river water of two recreational areas in Selangor, Malaysia. Trop Biomed. 2009;26(3):289-302.

16. Ben Ayed L, Schijven J, Alouini Z, Jemli M, Sabbahi S. Presence of parasitic protozoa and helminth in sewage and efficiency of sewage treatment in Tunisia. Parasitol Res. 2009;105(2):393-406.

17. Hajdu A, Vold L, Ostmo TA, Helleve A, Helgebostad SR, Krogh T, et al. Investigation of Swedish cases reveals an outbreak of cryptosporidiosis at a Norwegian hotel with possible links to in-house water systems. BMC Infect Dis. 2008;8:152.

18. Basualdo J, Pezzani B, Luca MD, Cordoba A, Apeztegua M.
Screening of the municipal water system of La Plata, Argentina, for human intestinal parasites. Int J Hyg Environ Health. 2000;203(2):177-82.

19. Farias EWC, Gamba RC, Pellizari VH. Detection of Cryptosporidium spp. oocysts in raw sewage and creek water in the city of São Paulo, Brazil. Braz J Microbiol. 2002;33(1):41-3.

20. Plutzer J, Karanis P, Domokos K, Torokne A, Marialigeti K. Detection and characterisation of Giardia and Cryptosporidium in Hungarian raw, surface and sewage water samples by IFT, PCR and sequence analysis of the SSUrRNA and GDH genes. Int J Hyg Environ Health. 2008;211(5-6):524-33.

21. Nichols RA, Campbell BM, Smith HV. Identification of Cryptosporidium spp. oocysts in United Kingdom noncarbonated natural mineral waters and drinking waters by using a modified nested PCR-restriction fragment length polymorphism assay. Appl Environ Microbiol. 2003;69(7):4183-9.

22. Ziae HJH, Yousefi Z, Mohammadpour R. Parasitic Contamination of Wells Drinking Water in Mazandaran Province in 2002-2003. J Kermanshah Univ Med Sci . 2006;10(4):378-88.

23. Manouchehri Naeini K, Asadi M, Hashemzade Chaleshtori M. Detection and Molecular Characterization of Cryptosporidium species in Recreational Waters of Chaharmahal va Bakhtiyari Province of Iran using nested-PCR-RFLP. Iran J Parasitol. 2011;6(1):20-7.

24. Nanbakhsh H, Hazratitapeh K, Diba K. Parasitic contamination and some chemical and physical features of water of indoor public swimming pools of Oorumieh city in 2001.J Kermanshah Univ Med Sci . 2005;9(4):1-11.

25. Rasti S, Asadi M, Iranshahi L, Hooshyar H, Gilasi H, Zahiri A. Evaluation of parasitic and fungal contamination and physicochemical parameters of indoor public swimming pools in Kashan during 2008-2009. Journal of Kashan University of Medical Sciences 2011;15(1):77-83.

26. Anonymous . Systematic review of waterborne disease outbreaks following extreme water events.: Communicable Disease Surveillance Centre, Public Health Wales.; 2011. 